\title{
DIGITAL ENTREPRENEURSHIP THROUGH SOCIAL MEDIA FOR START-UP BUSINESSES IN THE REPUBLIC OF NORTH MACEDONIA
}

\section{Tea JOSIMOVSKA ${ }^{1}$, Ana JOSIMOVSKA ${ }^{2}$, Fani MATESKA PEROVSKA ${ }^{3}$, Martin KISELICKI 4}

\author{
1Institute of Economics, Prolet 1,1000 Skopje, Republic of N. Macedonia \\ 2Faculty of Engineering and Information Technologies, Rudger Boskovic, 18, 1000 Skopje, \\ Republic of N. Macedonia \\ 3"Spock i Navis dooel Skopje", Str. Filip Vtori Makedonski 3, floor 2, 1000 Skopje, Republic of \\ N. Macedonia \\ ${ }^{4}$ Faculty of economics, Blvd. Goce Delcev 9V 1000 Skopje, Republic of N. Macedonia \\ *Correspondence: tea.josimovska@gmail.com
}

\begin{abstract}
Recent changes in the digital landscape, especially evident through the emergence of the COVID-19 pandemic have shifted the boundaries and obstacles of ecommerce. As the startup businesses comprise the moving force of national economies, there is an increase of a new type of entrepreneurship initiative, called digital entrepreneurship. By utilizing ICT and the Internet, the paper examines the foundations and forces behind the digital entrepreneurship, and whether they can be translated into benefits for entrepreneurs in the Republic of North Macedonia.

As shown by data from the state, one of the biggest challenges North Macedonian start-ups face is financial capacity and market stability. Through one of the dimensions of digital entrepreneurship, social media communication and marketing, the research is focused whether the new digital entrepreneur can achieve greater and more consistent sales numbers through e-commerce.

Based on the research and analysis of both secondary and primary data, a positive correlation can be seen between social media communication and the increase in online purchasing intention of consumers, represented by several different determinants. This entails managerial implication in rethinking the marketing strategy of a start-up business, which has traditionally focused mostly on utilizing social media as a complementary channel or not using it at all, and shifting towards a model of social e-commerce which shows future promise and potential.
\end{abstract}

KEYWORDS: Digital entrepreneurship, startup businesses, digital entrepreneur, marketing strategy, social e-commerce

JEL CLASSIFICATION: L26, M31 


\section{INTRODUCTION}

Through recent years, ICT technologies have shaped new opportunities for entrepreneurs and start-up businesses. The focus has started shifting initially with the Internet as an additional channel for sales, with complete digital transformation of all business processes in the following period. This resulted in the establishment of digital entrepreneurship, which encompasses various different ICT technologies at its foundation. Entrepreneurship is regarded as the cornerstone of the modern economy, with countries having a dominant number of start-up and micro businesses compared to other sizes. In the Republic of North Macedonia, where most of the registered companies fall under the micro category (under 10 employees) with $82.1 \%$ and small category (8.3\%), followed by medium companies (9.3\%). Corporations (over 250 employees) account for only $0.3 \%$ of all active registered companies ${ }^{1}$.

There are specific digital developments have had an impact on entrepreneurship, as well as businesses of various sizes (whether SMEs or corporations) to rethink and reshape their existing business and communication models, which are presented in Figure 1.

Figure 1. Elements of Digital Entrepreneurship

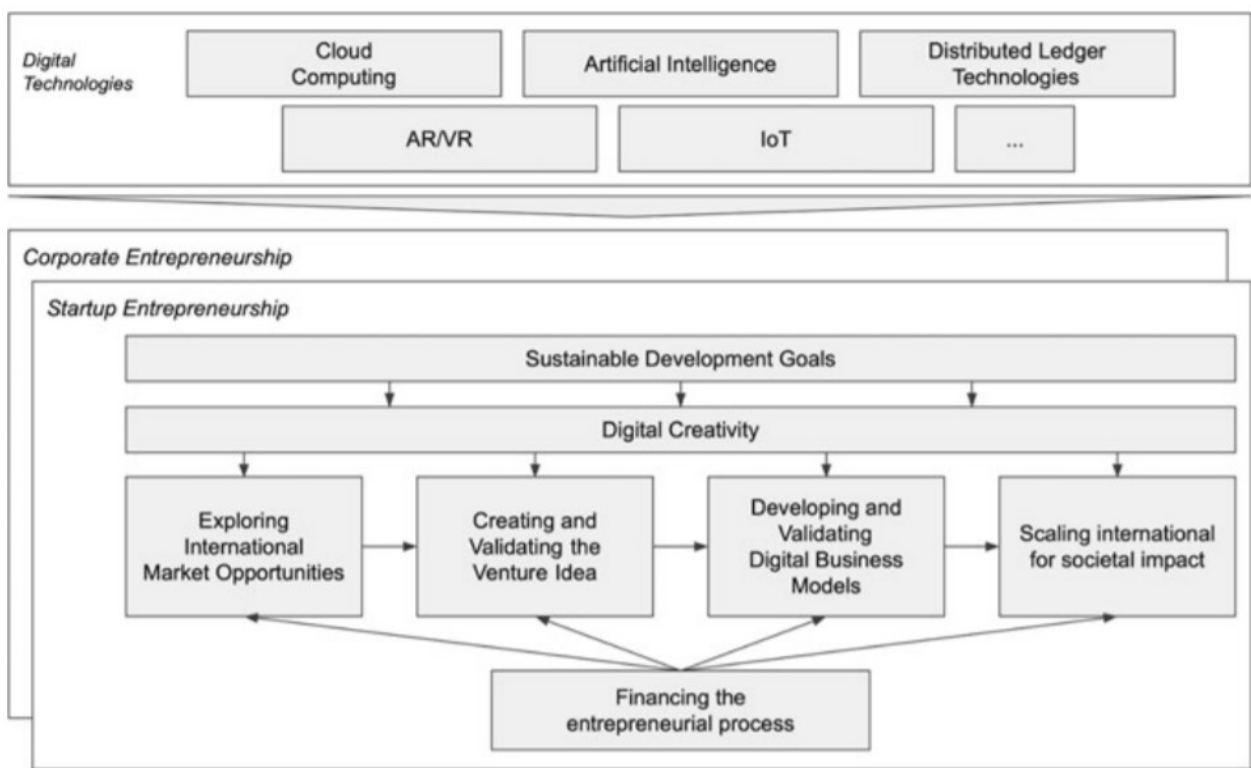

Source: Soltanifar et al., 2021

\footnotetext{
${ }^{1}$ https://www.stat.gov.mk/PrikaziSoopstenie.aspx?id=79\&rbr=13589
} 
As the business landscape and resources are constantly changing, start-ups have a larger array of digital tools and platforms to leverage for a successful launch. One of the most prominent communications channels in recent years have been social media, especially evident during pandemic times with high usage rates, presented in Figure 2.

Figure 2. Social media usage by platform

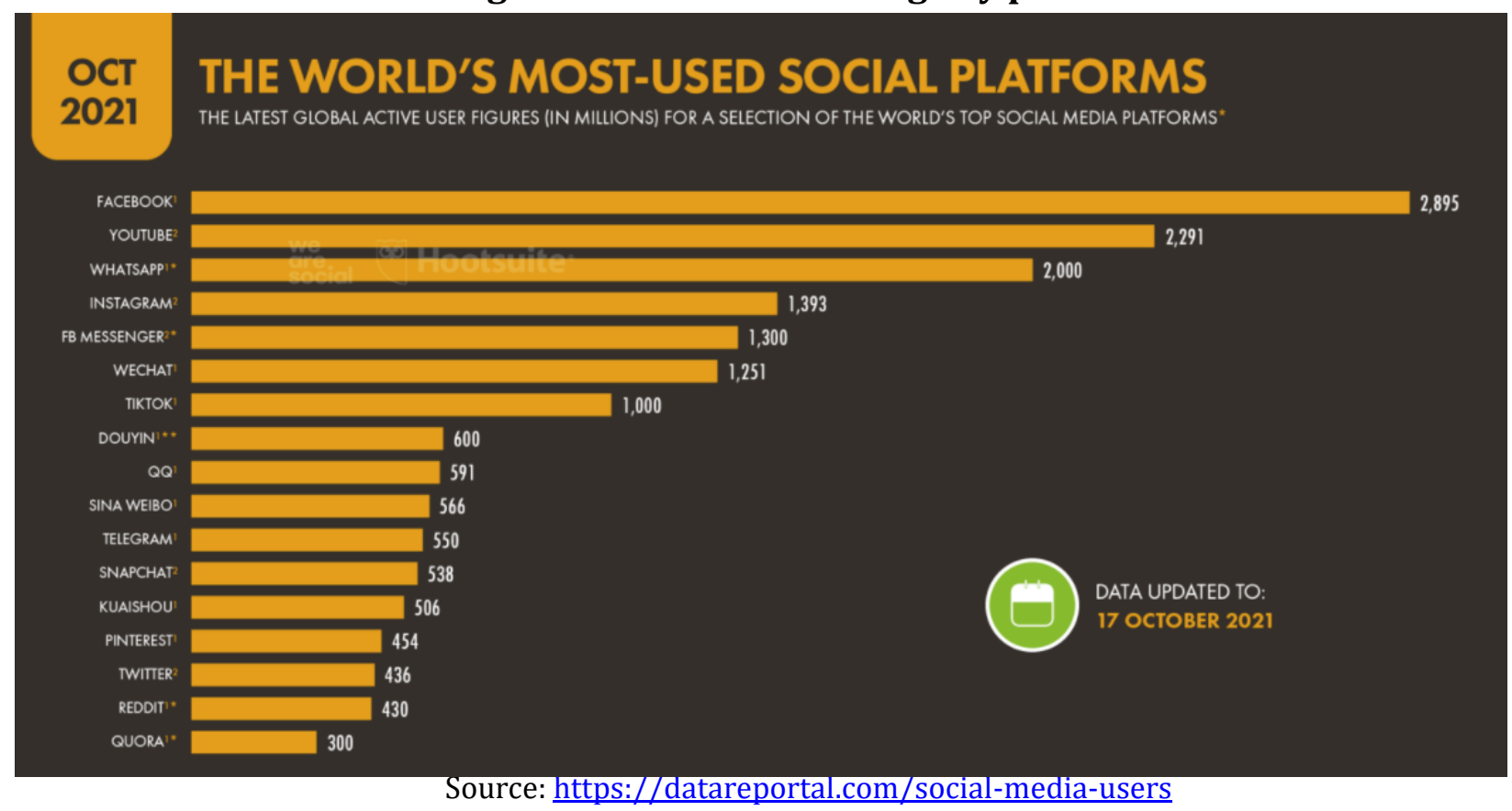

Facebook traditionally holds the first place, however there is a significant rise in YouTube, WhatsApp and Facebook Messenger as social media platforms used by consumers. This is in line with the prevalent word of mouth influence which has been noted in the past years (Alhidari et al., 2015). On YouTube, users can create videos related to the brand; "unboxing" their products, event footage or amateur commercials (Pace, 2008; Smith et al., 2012). According to Ertimur and Gilly (2012), these videos attract potential buyers much more than market-generated videos. The third and fifth most popular social networking platforms are WhatsApp and Facebook Messenger, respectivelly. Unlike Facebook and YouTube, they are classified as platforms for messaging, chatting or calling. WhatsApp has built its business platform to enable businesses to have a relevant business profile, provide customer support and share news with customers about their new products or services. For small businesses, there are built-in features, such as WhatsApp Business application, while for medium and 
large businesses, there is a WhatsApp Business API. Facebook has made Messenger a standalone application and currently has over one billion and three hundred million users. Businesses can now advertise, create chat communications, send newsletters and much more through Messenger. By combining aspects of digital entrepreneurship with the communication power of social media, entrepreneurs can reach audiences at reduced costs, with potentially greater effect on sales. As social media tends to be more personal, this new approach enables entrepreneurs to quickly launch and present their products and services to the general public, while offering an immediate conversion point. The potential increase in e-commerce sales could enable sooner scaling of the start-up and moving through the stages of the company lifecycle, which is researched as the main topic in this paper.

\section{LITERATURE REVIEW}

Entrepreneurship has many different definitions and has evolved throughout the years. Some authors define entrepreneurs as "individuals who exploit a market opportunity through technical and organization innovation" (Schumpeter, 1965), while others see entrepreneurs as "having characteristics of seeking opportunities, taking risks and having the tenacity to push an idea through to reality combine into a special perspective" (Kuratko, 2005). The prevalent elements of entrepreneurship can be seen as innovation and creativity, which start the process of entrepreneurship and the entrepreneurial path, leading to the creation of a start-up company.

\section{Figure 3. Lifecycle of start-ups}

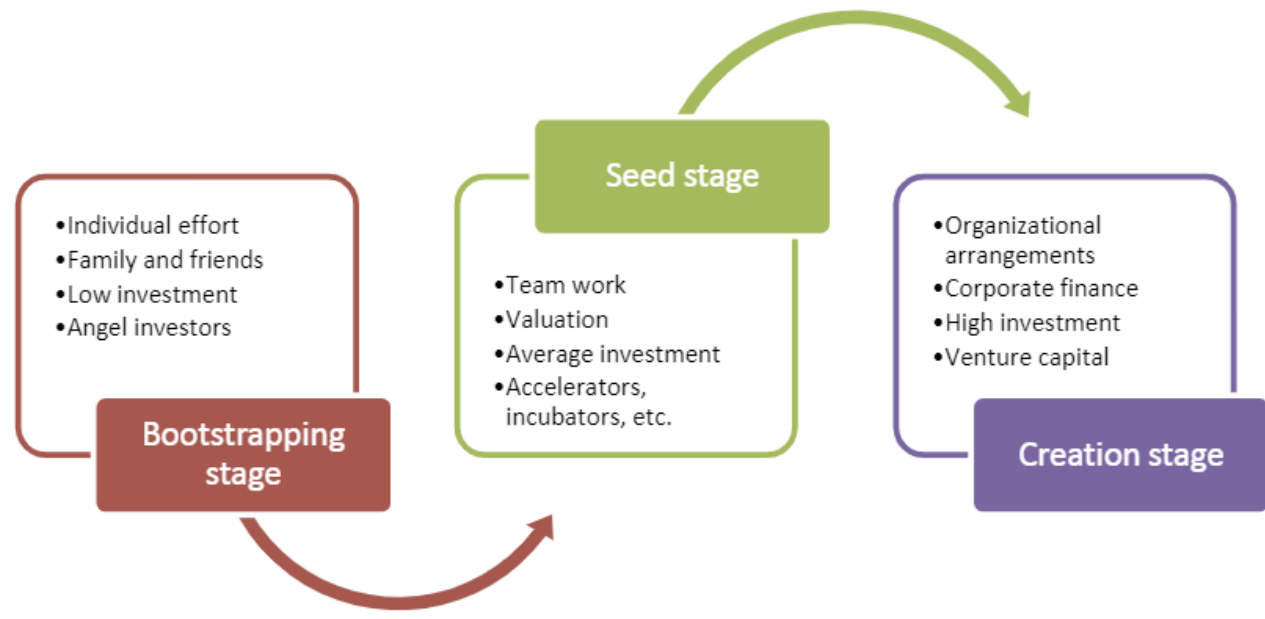

Source: Salamzadeh \& Kawamorita, 2015 
Figure 3 presents stages in the lifecycle of start-ups, which is based on a more traditional model preceding ICT and the Internet. At each stage there are different activities which can be deemed necessary for a start-up to successfully function. Some authors believe that the seed stage is critical for a successful start-up and can generally be seen as the stage where most initiative fall through. Most common obstacles startups face can include financial challenges, support mechanisms and environmental elements (Salamzadeh, 2015). In the Republic of North Macedonia during pandemic times, statistics show that the biggest obstacles for start-ups organization of work with $47 \%$ of companies, investments and financial stability with $49 \%$ and market sales and stability with 59\% (FITR, 2021). However, changes (and omittance) of certain elements in the activities and stages can be viewed through digital entrepreneurship. In modern times, businesses navigate five trends that shape the digital future of business - mobile computing, cloud computing, social media, IoT (Internet of Things) and Big Data (Valacich \& Schneider, 2018). This transformation has slowly begun at the end of the previous century, where organizations were labeled as either brick-andmortar, brick-and-click and click-and-mortar (Saeed et al., 2003). Digital entrepreneurship, differs from the traditional model, as it involves entrepreneurial pursuits which occur exclusively on a digital platform (Giones, 2017). In turn, this involves digital assets, meaning products and services can become digital, although this is not considered an exclusive form for the notion. As digitalization of the organization is considered difficult for larger organizations, start-ups can be the natural place for this type of change to happen (Antonizzi \& Smuts, 2020).

Of the five digital entrepreneurship trends, social media can potentially help with the biggest obstacle Macedonian start-ups face in recent years - generating market sales on a consistent basis. Recent research has found that the online purchasing intention depends on the following variables: attitude, buying impulse, subjective norms and the perceived usefulness (Pena Garcia et al., 2020). The rise of e-commerce and the development of social networks are introducing a new form of online shopping called "social e-commerce". According to Huang \& Benyoucef (2013), social e-commerce is defined commercial application of the Internet related to social media and technologies, based on social interaction and content generated by Internet users in order to help consumers make decisions about it. The goal of social e-commerce is to 
develop more social and interactive approaches or platforms that will allow customers to express themselves and share their experiences with other potential buyers as well as business entities.

\section{METHODOLOGY}

The research for the paper is conducted according to a pre-defined research plan, as follows: clearly set research goals, precisely defined survey questions, specifically defined sample of respondents and appropriate statistical techniques for data analysis and prediction of results. Qualitative and quantitative methods were used for the needs of the research. Quantitative methods are used to examine the relationships between dependent variables and the independent variable and to test hypotheses based on the data collected, while qualitative methods are used to lay the groundwork for research and define research questions. The research takes place in several phases, as follows: first, a detailed review of the literature is made in terms of models and methods used in these types of research and the needs and objectives of the research are defined. In the second phase, an online questionnaire was created and data from 350 respondents from a randomized sample were collected.

\section{RESEARCH AND DISCUSSION}

The research questionnaire was filled by 350 respondents, focusing on users who already had an experience with online shopping. Of these, $91 \%$ or 320 respondents are female, and the remaining $9 \%$ are male. In terms of age, $34 \%$ of respondents are aged 26 to 33 years, $32 \%$ are aged 34 to 41 years, 15\% are aged 42 to 49 years, $11 \%$ are aged 18 to 25 years, and $7 \%$ are over 50 years old.

Figure 4: Frequency of social media profile visits

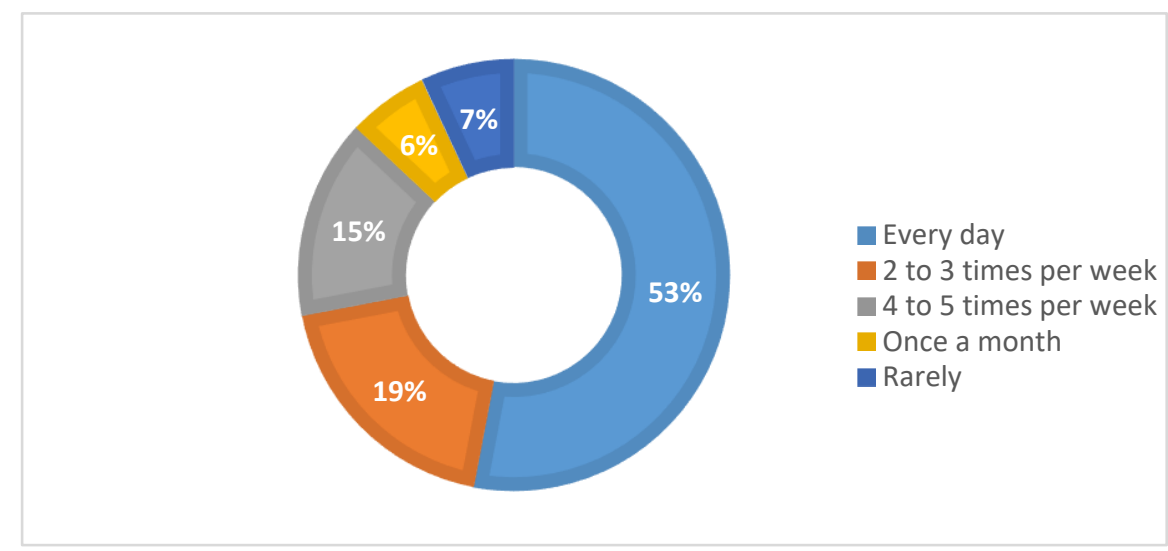


Source: Own research

As shown in Figure 4, as many as $53 \%$ of the respondents visit the social media profiles of the online stores where they buy the desired products every day, 19\% visit them 2 to 3 times a week, 15\%, visit them 4 to 5 times a week, $7 \%$ of respondents visit them very rarely, and the remaining $6 \%$ visit them once a month, which indicates the fact that online shoppers really use social media as a moderator in making decisions about buying products.

\section{Figure 5: Frequency of utilizing chat tools on social media and web-sites}

口Always Regularly Sometimes $\square$ Never

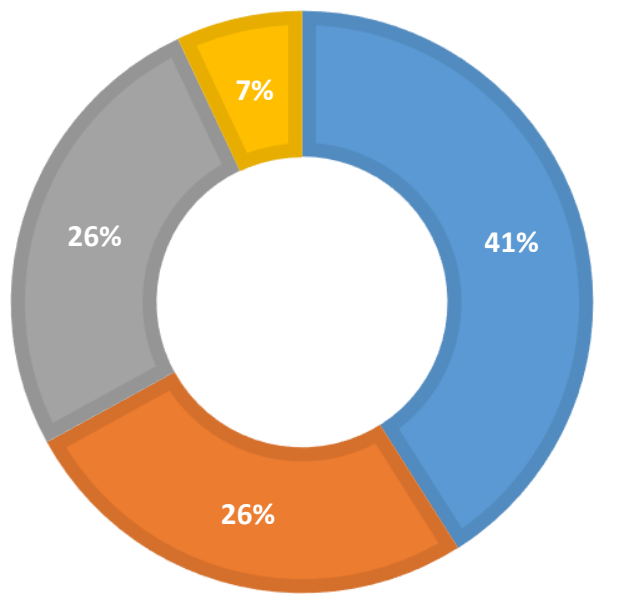

Source: Own research

\section{Figure 6: Frequency of viewing ads} and comments on social media

always $\square$ Regularly $\square$ Sometimes $\square$ Never

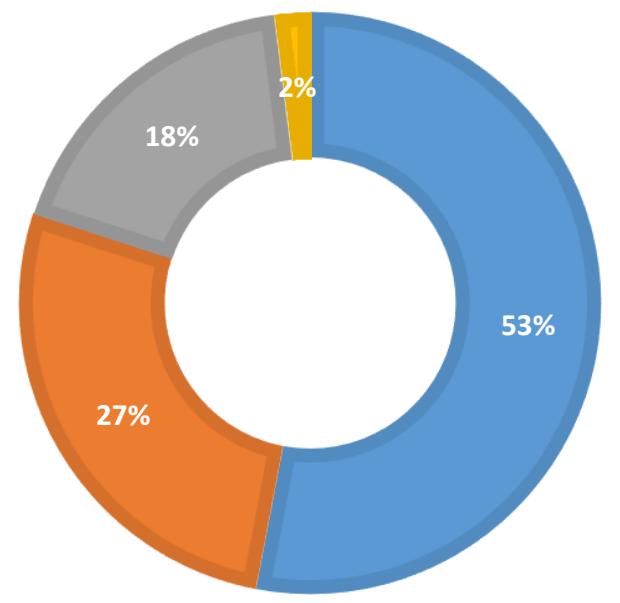

Source: Own research

The results presented in Figure 5 indicate that online shoppers always apply communication chats and Facebook messenger to collect enough messages about products before making final purchasing decisions. Namely, as many as $41 \%$ of the respondents stated that they always use communication chats, and only $7 \%$ do not communicate with online shoppers before buying products. The percentage of respondents is only $26 \%$, who often or sometimes use these chats for communication or Facebook messenger. Regarding the frequency of reading reviews and comments on the Internet about the products, the results presented in Figure 6 indicate that as many as $53 \%$ of respondents always read reviews and comments, $27 \%$ of them read them 
often, $18 \%$ of respondents sometimes read them, and only $2 \%$ of respondents never read product reviews on the Internet.

For the needs of the research, an analysis was made of the data obtained from the online questionnaire, ie the impact of the determinants of the messages transmitted through the Facebook pages to the online stores. To analyze this impact, a Likert scale with a rating of respondents's answers from 1 to 5 is applied.

Table 1: Descriptive analysis of the influence in communication determinants through social media

\begin{tabular}{|c|c|c|c|}
\hline Variable & Question & Average value & Standard deviation \\
\hline \multirow{3}{*}{$\begin{array}{l}\text { Quality of } \\
\text { communication }\end{array}$} & KVP1 & 3.17 & 0.90 \\
\hline & KVP2 & 3.19 & 1.03 \\
\hline & KVP3 & 2.86 & 0.99 \\
\hline \multirow[t]{3}{*}{ Start-up credibility } & KRP1 & 2.80 & 1.04 \\
\hline & KRP2 & 2.77 & 1 \\
\hline & KRP3 & 3.66 & 1.07 \\
\hline \multirow{3}{*}{$\begin{array}{l}\text { Need for } \\
\text { communication }\end{array}$} & PP1 & 4.23 & 1.05 \\
\hline & PP2 & 4.20 & 1.08 \\
\hline & PP3 & 4.22 & 1.07 \\
\hline \multirow{3}{*}{$\begin{array}{l}\text { Attitude toward } \\
\text { communication }\end{array}$} & SP1 & 4.36 & 0.96 \\
\hline & SP2 & 3.51 & 1.10 \\
\hline & SP3 & 2.83 & 1.31 \\
\hline \multirow{2}{*}{$\begin{array}{l}\text { Usefulness of } \\
\text { communication }\end{array}$} & KOP1 & 3.85 & 1.03 \\
\hline & KOP2 & 3.25 & 1.12 \\
\hline \multirow{3}{*}{$\begin{array}{l}\text { Acceptance of } \\
\text { messages }\end{array}$} & PRP1 & 3.45 & 1.15 \\
\hline & PRP2 & 3.77 & 1.08 \\
\hline & PRP3 & 3.67 & 1.12 \\
\hline \multirow{6}{*}{$\begin{array}{l}\text { Influence in online } \\
\text { purchasing behaviour }\end{array}$} & NMK1 & 4.02 & 1.08 \\
\hline & NMK2 & 3.74 & 1.22 \\
\hline & NMK3 & 3.76 & 1.20 \\
\hline & NMK4 & 4.13 & 1.18 \\
\hline & NMK5 & 4.23 & 1.13 \\
\hline & NMK6 & 4.23 & 1.12 \\
\hline
\end{tabular}

Source: Own research 
From the conducted descriptive analysis and the obtained results given in Table 1, it can be concluded that the statement, ie the statement: "I always read the messages about the same product (SP1)" has the highest absolute mean value, 4.36 , or the highest significance for further research, which means that this attitude of the respondents towards the product reviews, which they read on social media, has the greatest impact on the intentions of online shopping. On the other hand, the statement "Product messages are credible (KRP2)" has the lowest absolute mean, 2.77, ie the lowest significance for further research, which means that this statement, which describes the authenticity of messages, as part of their credibility, has least impact on online shopping intentions.

The determinants of the messages were specifically analyzed, which concluded that their impact on the intentions for online shopping is common, ie they can not be analyzed without each other, each determinant influencing social e-commerce in a significant manner. The quality and credibility of messages for key determinants in making final purchasing decisions by customers. Namely, if buyers perceive the messages, ie the information offered about the products on the Internet as low quality and negative, it will be much harder to decide to buy the desired products and vice versa, if they perceive the online messages for quality and positive, much faster will make purchasing decisions. Also, online shoppers, before they start searching the Internet, have precisely defined needs for buying certain products, which directly affect their purchase intentions. Hence, they can develop, positive or negative, as well as strong and weak attitudes towards certain information that is placed on the Internet about the products they want to buy.

\section{CONCLUSION}

Transforming the communication between companies and consumers on a social media platform serves as a positive basis for the beginning of social e-commerce. Communication messages are more susceptible to influence the online purchasing decision if they have high quality, are accurate and credible, useful and accepted by customers, then it can be said that this communication is positive and that it affects the intentions for online shopping in the form of buying decisions. These determinants, 
along with the needs and attitudes of online shoppers, are a successful combination of guaranteed online shopping decisions made by online shoppers.

The analysis of the determinants of online messages and the analysis of their impact on the intentions for online shopping achieved the main goal of this research which was to research the impact of the determinants of social media on the intentions of online shopping, which affects the element of social e-commerce sales for a start-up. The results of the research create significant managerial implications, because the impact of the determinants on the social media communication is evident in several different determinants. This is especially important for start ups who can advertise their digital products and services on social media, however it can also be applied for traditional (non-digital) products and services. In this context, start ups need to adapt their online marketing strategies to successfully promote and sell their products on social media. The research can be expanded in two directions. First, the same research methodology can be performed in other countries in the Balkan region, which will generate relevant results for start-ups on a larger scale, as well as verify results between countries. Second, the research can be expanded in other areas which are relevant for startup businesses outlined in the literature review (such as financial capacity, organizational capacity and etc.) by introducing new determinants influencing internal and external factors.

\section{REFERENCES}

○ Alhidari, A., Iyer, P., \& Paswan, A. (2015). Personal level antecedents of eWOM and purchase intention, on social networking sites. Journal of Customer Behaviour iss. 14

- Antonizzi J., Smuts H., (2020), The Characteristics of Digital Entrepreneurship and Digital Transformation: A Systematic Literature Review, I3E 2020: Responsible Design, Implementation and Use of Information and Communication Technology

- Giones F, Brem A., (2017), Digital technology entrepreneurship: a definition and research agenda. Technol. Innov. Manag.;7(5)

- Ertimur, B. and Gilly, M.C. (2012) "So Whaddya Think? Consumers Create Ads and Other Consumers Critique Them", Journal of Interactive Marketing, 26(3)

○ Huang Z. Benyoucef M. (2013), From e-commerce to social commerce: A close look at design features, Electronic Commerce Research Appllications, Vol. 12

- Kuratko, D. F. (2005). The emergence of entrepreneurship education: Development, trends, and challenges. Entrepreneurship Theory and Practice, 29(5), 577-598.

- N. Peña García, I. Gil-Saura, A. Rodríguez-Orejuela, J.R. Siqueira-Junior (2020), Dataset Purchase Intention and Purchase Behavior Online: A Cross-Cultural Approach, Heliyon, Volume 6, Issue 6, ISSN 2405-8440

- Pace, S. (2008), YouTube: an opportunity for consumer narrative analysis?, Qualitative Market Research: An International Journal, 11(2) 
- Saeed, K. A., Grover, V. and Hwang, Y. (2003). 'Creating Synergy with a Clicks and Mortar Approach', Communications of the ACM 46(12)

- Salamzadeh A., Kawamorita H., (2015), Startup Companies: Life Cycle and Challenges, The 4th International Conference on Employment, Education and Entrepreneurship (EEE)

- Salamzadeh, A. (2015). New Venture Creation: Controversial Perspectives and Theories. Economic Analysis, 48(3/4).

- Schumpeter J. A. (1965). Economic Theory and Entrepreneurial History. In: Aitken HG (ed) Explorations in enterprise. Harvard University Press, Cambridge, MA

- Smith, A.N., Fischer, E. and Yongjian, C. (2012), How Does Brand-related User generated Content Differ across YouTube, Facebook, and Twitter?, Journal of Interactive Marketing, volume 26, issue 2

- Soltanifar M., Hughes M., Gocke L., (2021), Digital Entrepreneurship - Impact on Business and Society, Springer, ISBN 978-3-030-53913-9

- Valacich, J. S., \& Schneider, C. (2018) Information systems today: managing in the digital world, 8th edn. Pearson.

\section{Internet sources:}

- FITR (2021), Risks and Measures for Economic Healing of Startups, available at https://fitr.mk/wpcontent/uploads/2021/11/PREZENTACIJA-FITR.pdf

○ https://www.stat.gov.mk/PrikaziSoopstenie.aspx?id=79\&rbr=13589

○ https://datareportal.com/social-media-users 